\title{
A Research on the Fair Play Behaviors of Students Participating in School Sports (The Case of Düzce Province)
}

\author{
Levent GORUN \\ Düzce University Faculty of Sports Science, Düzce, Turkey. \\ Email:leventgorun@hotmail.com Tel: +905325096179
}

\section{Abstract}

The aim of this study is to examine the fair play behaviours of students who attend school sports. The universe of the research is 2631 participants studying in the Central District of Düzce in the 2019-2020 Academic Year and competing in volleyball, basketball, football and individual branches in secondary and high schools, while the sample is 397 participants on a voluntary basis. In the research, the personal information form created by the researchers and "Fair Play Scale" (FP) developed by Efe (2006) were used as a measurement tool. The scale consists of four subscales: "pre-match fair play", "during-match fair play", "after-match fair play" and "general fair play in a match". While there is a statistically significant difference in all subscales according to the categories, when compared to the sports age, there is a statistical difference only in the fair play behaviours during the match. Also, when fair play behaviours are compared according to the branch, a statistically significant difference is observed according to the subscales of pre-match, during the match and general fair play behaviours. As a result, it can be said that fair play behaviours, which vary according to the branch, sports age and categories, can be spread to social life after school with trainings suitable for the development periods and the requirements of the sports branches.

Keywords: Fair play, School sports.

Citation | Levent GORUN (2020). A Research on the Fair Play Behaviors of Students Participating in School Sports (The Case of Düzce Province). Asian Journal of Education and Training, 6(3) 356-361.

History:

Received: 16 March 2020

Revised: 20 April 2020

Accepted: 22 May 2020

Published: 8 June 2020

Licensed: This work is licensed under a Creative Commons

Attribution 3.0 License (oc))

Publisher: Asian Online Journal Publishing Group
Funding: This study received no specific financial support

Competing Interests: The author declares that there are no conflicts of interests regarding the publication of this paper.

Transparency: The author confirms that the manuscript is an honest, accurate, and transparent account of the study was reported; that no vital features of the study have been omitted; and that any discrepancies from the study as planned have been explained.

Ethical: This study follows all ethical practices during writing

\section{Contents}

1. Introduction

3. Results. 


\section{Contribution of this paper to the literature}

This study contributes to existing literature by examining the fair play behaviours of students who attend school sports.

\section{Introduction}

The understanding of sports, which has been going on for years, has started to change with the birth of professional sports and the significant dominance of economic factors on sports. Sports for game, entertainment and health has become an activity where winning is at the forefront and competition is at a high level. Thus, sports activities that should be based on values such as love, friendship, peace and sportsmanship have started to become a current issue and to be mentioned because of violence events that are often incompatible with the spirit of sportsmanship (Tanrıverdi, 2012). This situation also harms sustainable fair sports environments. Especially increasingly continuing commercial and political expectations from sports have pushed moral expectations to the second plan. This, in turn, has led to sports to go out of its true philosophy (Sezen \& Yıldıran, 2007). Winning and that the money is at the forefront can lead to increased violence in sports. Unfortunately, the emergence of violence in sports negatively affects the development of sports. It is necessary to focus on what needs to be done to find the causes of violence and increase fair play (Adilogullari, Hakkı, Enes, \& Ihsan, 2017). One of the most important concepts that will keep sport alive and contribute to a sustainable sports environment is "Fair Play". Fair Play is defined as "compliance" respect for officials and their decisions, and respect for other competitors". In addition, Fair Play is associated with generosity in play, humility in victory, and elegance in defeat. These obligations apply to anyone involved in the sport, such as competitors, parents, coaches, officials, leaders or supporters (Loland, 2002). As Gülfem (2014) states, unfair behaviours related to Fair Play cannot be behaviours that may change according to the results or importance of the competitions. In order to develop Fair Play understanding in sports and contribute to a more sustainable sports environment, necessary trainings are expected in the youth academy. In order for children and young people who will be the future of sports to behave in accordance with Fair Play, it is necessary to raise awareness among children and young people involved in youth academy and school sports. Even in school sports, in which children of school age participate, the motive to win has come to the fore. Besides sportsmanship sports institutions, it can also be taught through practices in schools and through the implementation of educational programs and educational resources (Ford, Jubenville, \& Phillips, 2012). The moral and humanitarian general goals of school sports can be expressed as arousing physical, mental and social health consciousness in children and young people and gaining these values to them (Pehlivan, 2004). Sports activities carried out in schools through physical education lessons play an important role in the internalization of human values such as developing a sense of solidarity and cooperation in children and young people, creating rule awareness, sharing, justice, tolerance and helpfulness (Kayışlığlu, Altınkök, Temel, \& Yüksel, 2015). In order to raise a young generation having ethical equipment, it is important to start Fair Play studies in primary and secondary school children's and young people's physical education lessons as they are going to be the future athletes, trainers, sportsmen, referees, writers and spectators (Ylldiran, 2002). In this context, this study aims to examine the fair play behaviours of students who are the infrastructure of sports and participate in school sports, which will contribute to the spread of Fair Play concept to sports environments.

\section{Methodology}

This study, which examines the fair play behaviours of students doing volleyball, basketball, football and some individual sports, is in the screening model. Research approaches that aim to describe a situation that existed in the past or present as it exists are called the screening model (Karasar, 2005). While the universe of the research is 2631 (Volleyball $=754$, Basketball $=420$, Football=875, Individual=582) participants studying in the Central District of Düzce in the 2019-2020 Academic Year and competing in volleyball, basketball, football and individual branches (excluding those ranked by team point) in secondary and high schools, the sample is 397 (Volleyball=112, Basketball $=81$, Football $=127$, Individual $=77$ ) participants on a voluntary basis.

In the research, the personal information form created by the researchers and "Fair Play Scale" (FP) developed by Efe in 2006 were used as a measurement tool. The scale consists of four subscales: "pre-match fair play", "during-match fair play", "post-match fair play" and "general fair play in a match". In the FP scale consisting of 21 items, questions numbered 1, 2, 3, and 4 measure "pre-match fair play" subscale. The questions numbered 5, 6, 7, $11,12,13$ and 14 measure "during-match fair play" subscale. The questions numbered 17, 1819,20 and 21 measure "post-match fair play" subscale and questions numbered 8, 9, 10, 15, 16 measure "general fair play in a match" subscale. When FP internal consistency coefficients are analysed, it has been identified that "pre-match fair play = 0.765 ", "during-match fair play $=0.780$ ", "post-match fair play $=0.829$ ", "general fair play in a match $=0.671$ " and "Total Test $=0.852$ ". For this study, Cronbach Alpha values have been found 0.70, 0.78, 0.79, $0.65,0.74$, respectively.

\subsection{Data Collection and Analysis}

The collected data were analysed on the computer based on total scores. Kolmogorov Smirnov Test was applied for the normality of the data. For non-normally distributed data, Kruskal Wallis Test was used for intragroup comparisons and MannWhitney-U Test was used for inter-group comparisons. The significance level was accepted as 0.05, 0.01 and 0.001 in all statistical analyses. 


\section{Results}

Table-1. Comparison of fair play scale subscales by categories.

\begin{tabular}{|c|c|c|c|c|c|c|c|}
\hline & Category & $\mathbf{n}$ & Mean Rank & sd & $\mathrm{X}^{2}$ & p & Between Groups Difference \\
\hline \multirow{4}{*}{ Pre- match } & Minors $^{1}$ & 74 & 176.28 & \multirow{4}{*}{3} & \multirow{4}{*}{8.24} & \multirow{4}{*}{$0.041^{*}$} & \multirow{4}{*}{$\begin{array}{c}1-3 \mathrm{p}=0.009^{*} * \\
3-4 \mathrm{p}=0.032^{*}\end{array}$} \\
\hline & Stars $^{2}$ & 133 & 202.96 & & & & \\
\hline & JuniorsB $^{3}$ & 106 & 220.75 & & & & \\
\hline & JuniorsA $^{4}$ & 84 & 185.30 & & & & \\
\hline \multirow{4}{*}{ During-match } & Minors $^{1}$ & 74 & 161.93 & \multirow{4}{*}{3} & \multirow{4}{*}{29.77} & \multirow{4}{*}{$0.000 * * *$} & \multirow{4}{*}{$\begin{array}{c}1-3 \mathrm{p}=0.002^{*} * \\
1-4 \mathrm{p}=0.000^{*} * \\
2-3 \mathrm{p}=0.016^{*}, \\
2-4 \mathrm{p}=0.000^{*} * \\
3-4 \mathrm{p}=0.037^{*}\end{array}$} \\
\hline & Stars $^{2}$ & 133 & 177.48 & & & & \\
\hline & JuniorsB $^{3}$ & 106 & 213.62 & & & & \\
\hline & JuniorsA ${ }^{4}$ & 84 & 247.29 & & & & \\
\hline \multirow{4}{*}{ Post-match } & Minors $^{1}$ & 74 & 190.78 & \multirow{4}{*}{3} & \multirow{4}{*}{8.75} & \multirow{4}{*}{$0.033^{*}$} & \multirow{4}{*}{$\begin{array}{c}2-4 \mathrm{p}=0.004^{* *} \\
3-4 \mathrm{p}=0.036^{*}\end{array}$} \\
\hline & Stars $^{2}$ & 133 & 216.09 & & & & \\
\hline & JuniorsB ${ }^{3}$ & 106 & 204.96 & & & & \\
\hline & JuniorsA $^{4}$ & 84 & 171.65 & & & & \\
\hline \multirow{4}{*}{ General } & Minors $^{1}$ & 74 & 162.24 & \multirow{4}{*}{3} & \multirow{4}{*}{14.81} & \multirow{4}{*}{$0.002^{* *}$} & \multirow{4}{*}{$\begin{array}{c}1-2 \mathrm{p}=0.012^{*}, 1-4 \\
\mathrm{p}=0.000^{* * *} \\
3-4 \mathrm{p}=0.026^{*}\end{array}$} \\
\hline & Stars $^{2}$ & 133 & 203.30 & & & & \\
\hline & JuniorsB $^{3}$ & 106 & 194.39 & & & & \\
\hline & JuniorsA $^{4}$ & 84 & 230.39 & & & & \\
\hline
\end{tabular}

As a result of the analysis, when the fair play behaviours of the participants competing in school sports are analysed according to their categories, a statistically significant difference has been found in the subscale of pematch fair play, $\mathrm{X} 2(\mathrm{sd}=3, \mathrm{n}=397)=8.24, \mathrm{p} \leq 0.05$. When the mean ranks of the groups are analysed, it is seen that the students participating in school sports in the "Juniors B" category have the highest mean rank. It has been seen that those in the category "Stars" and "Juniors A" follow the people who compete in the "Juniors B" category, while the lowest average is among the participants in the "Minors" category. When it is analysed between in which groups the significant difference emerged, it has been found that it is in favour of the participants competing in the category of "Juniors B" between the "Minors and Junior B $(\mathrm{U}=3032.00, \mathrm{p} \leq 0.01)$ " and "Juniors B and Juniors A $(\mathrm{U}=3652.00, \mathrm{p} \leq 0.05)$ " categories.

When the fair play behaviours during the match are examined, it is seen that the lowest mean rank belongs to those in the "Minors" category, and the highest mean rank belongs to the "Juniors A" category. In addition, a significant difference has emerged in the statistical analysis, $\mathrm{X}_{2}(\mathrm{sd}=3, \mathrm{n}=397)=29.77, \mathrm{p} \leq 0.001$. It has been seen in favour of those in the "Juniors A" in all categories among those who compete in "Juniors A and Juniors B $(\mathrm{U}=3673.00, \mathrm{p} \leq 0.05)$ ", "Juniors A and Stars $(\mathrm{U}=3691.50, \mathrm{p} \leq 0.001)$ " and "Juniors A and Minors $(\mathrm{U}=1725.50$, $\mathrm{p} \leq 0.001)$ " categories. In addition, is has been determined that there is a significant difference in favour of those in the "Juniors B" category among those who compete in the "Juniors B and the Stars $(\mathrm{U}=5789.50, \mathrm{p} \leq 0.05)$ " and "Juniors B and the Minors ( $\mathrm{U}=2852.50, \mathrm{p} \leq 0.01$ )" categories.

When the post-match fair play behaviours by categories are analysed, it is understood that the highest mean rank is in the participants who compete in the "Stars" category and the lowest score is in the "Juniors A" category. Considering which groups are different, there is a statistically significant difference in favour of the "Juniors A" category in both comparisons in the categories "Stars and Juniors A $(\mathrm{U}=4331.50, \mathrm{p} \leq 0.01)$ " and "Juniors B and Juniors A (U=3673.00, $\mathrm{p} \leq 0.05)$ ".

When the general fair play behaviours are examined according to Table 1, there is a statistically significant difference, $\mathrm{X}_{2}(\mathrm{sd}=3, \mathrm{n}=397)=14.81, \mathrm{p} \leq 0.01$. When it is analysed in which groups there is statistically significant difference, it is seen that it is in favour of those in the category of "Stars" in the "Minors and Stars $(\mathrm{U}=3906.00, \mathrm{p} \leq 0.05)^{\prime}$ categories. It is in favour of those in the category of "Juniors A" in the "Minors and Juniors $\mathrm{A}(\mathrm{U}=2047.50, \mathrm{p} \leq 0.001)$ " and "Juniors B and Juniors A $(\mathrm{U}=3627.50, \mathrm{p} \leq 0.05)$ " categories.

Table-2. Comparison of fair play scale subscales by sports age.

\begin{tabular}{|c|c|c|c|c|c|c|c|}
\hline & Sports Age & $\mathbf{n}$ & Mean Rank & sd & $\mathrm{X}^{2}$ & p & Between Group Difference \\
\hline \multirow{3}{*}{ Pre-match } & $1-3 \mathrm{Y}_{1} \mathrm{l}^{1}$ & 126 & 185.94 & \multirow{3}{*}{2} & \multirow{3}{*}{4.79} & \multirow{3}{*}{0.091} & \\
\hline & 4-6 $\mathrm{Y}_{1}{ }^{2}$ & 164 & 196.53 & & & & \\
\hline & $7-9 \mathrm{Y}_{1}{ }^{3}$ & 107 & 218.16 & & & & \\
\hline \multirow{3}{*}{ During-match } & $1-3 \mathrm{Y}_{1}{ }^{1}$ & 126 & 163.55 & \multirow{3}{*}{2} & \multirow{3}{*}{36.34} & \multirow{3}{*}{$0.000^{* *}$} & $1-2 \mathrm{p}=0.033^{*}$ \\
\hline & 4-6 $\mathrm{Y}_{1}{ }^{2}$ & 164 & 191.74 & & & & $1-3 \mathrm{p}=0.000^{* *}$ \\
\hline & $7-9 \mathrm{Y}_{1}{ }^{3}$ & 107 & 251.87 & & & & $2-3 \mathrm{p}=0.000^{* *}$ \\
\hline \multirow{3}{*}{ Post-match } & $1-3 \mathrm{Y}_{1} 1^{1}$ & 126 & 198.80 & \multirow{3}{*}{2} & \multirow{3}{*}{0.001} & \multirow{3}{*}{1.000} & \\
\hline & 4-6 $\mathrm{Y}_{1}{ }^{2}$ & 164 & 199.04 & & & & \\
\hline & $7-9 \mathrm{Y}_{1} \mathrm{l}^{3}$ & 107 & 199.18 & & & & \\
\hline \multirow{3}{*}{ General } & $1-3 \mathrm{Y}_{1} 1^{1}$ & 126 & 187.52 & \multirow{3}{*}{2} & \multirow{3}{*}{2.96} & \multirow{3}{*}{0.228} & \\
\hline & 4-6 $\mathrm{Yll}^{2}$ & 164 & 198.72 & & & & \\
\hline & $7-9 \mathrm{Y}_{1}{ }^{3}$ & 107 & 212.94 & & & & \\
\hline
\end{tabular}

When the fair play behaviours of the participants according to the sports age are examined, it is revealed that the statistically significant difference is only in fair play behaviours during the match, $\mathrm{X} 2(\mathrm{sd}=2, \mathrm{n}=397)=36.31$, $\mathrm{p} \leq 0.001$. According to the mean rank, it is seen in Table 2 that those who have done sports for $7-9$ years have the highest mean rank. Also, according to Table 2 it can be said that the sports age and mean rank points showed a linear increase. Considering in which groups this statistical difference arises, it has been figured out that is in favour of those who have the sports age of "4-6 Years" among the groups of "1-3 Years and 4-6 Years (U=8852.50, 
$\mathrm{p} \leq 0.05)$ ", and in favour of those who have a sports age of "7- 9 Years" among the groups of "1-3 Years and 7- 9 years $(\mathrm{U}=3754.00, \mathrm{p} \leq 0.001)$ " and "4-6 Years and 7-9 Years $(\mathrm{U}=6103.50, \mathrm{p} \leq 0.001)$ ". There is no statistically significant difference in the pre-match, post-match and general fair play behaviours of the participants according to the sports age.

Table-3. Comparison of fair play scale subscales according to the branch in school sports.

\begin{tabular}{|c|c|c|c|c|c|c|c|}
\hline & Branch & $\mathbf{n}$ & Mean Rank & sd & $\mathbf{X}^{2}$ & p & Between Group Difference \\
\hline \multirow{4}{*}{ Pre- Match } & Volleyball $^{1}$ & 112 & 190.04 & \multirow{4}{*}{3} & \multirow{4}{*}{8.24} & \multirow{4}{*}{$0.001 * * *$} & \multirow{4}{*}{$\begin{array}{c}1-3 \mathrm{p}=0.015^{*} \\
2-4 \mathrm{p}=0.010^{* *} \\
3-4 \mathrm{p}=0.000^{* * *}\end{array}$} \\
\hline & Basketball $^{2}$ & 81 & 206.25 & & & & \\
\hline & Football $^{3}$ & 127 & 226.13 & & & & \\
\hline & Individual $^{4}$ & 77 & 169.67 & & & & \\
\hline \multirow{4}{*}{ During- Match } & Volleyball $^{1}$ & 112 & 153.97 & \multirow{4}{*}{3} & \multirow{4}{*}{29.77} & \multirow{4}{*}{$0.000^{*} * *$} & $1-2 \mathrm{p}=0.000^{* * *}$ \\
\hline & Basketball $^{2}$ & 81 & 233.68 & & & & $1-3 \mathrm{p}=0.000 * * *$ \\
\hline & Football $^{3}$ & 127 & 263.94 & & & & $1-4 \mathrm{p}=0.009^{*} *$ \\
\hline & Individual ${ }^{4}$ & 77 & 120.91 & & & & $\begin{array}{l}2-4 \mathrm{p}=0.000^{* * *} \\
3-4 \mathrm{p}=0.000^{* * *}\end{array}$ \\
\hline \multirow{4}{*}{ Post- Match } & Volleyball $^{1}$ & 112 & 220.09 & \multirow{4}{*}{3} & \multirow{4}{*}{8.75} & \multirow{4}{*}{0.121} & \\
\hline & Basketball $^{2}$ & 81 & 193.08 & & & & \\
\hline & Football $^{3}$ & 127 & 186.63 & & & & \\
\hline & Individual $^{4}$ & 77 & 194.94 & & & & \\
\hline \multirow{4}{*}{ General } & Volleyball $^{1}$ & 112 & 176.75 & \multirow{4}{*}{3} & \multirow{4}{*}{14.81} & \multirow{4}{*}{$0.000^{*} * *$} & $1-2 p=0.031^{*}$ \\
\hline & Basketball $^{2}$ & 81 & 213.95 & & & & $1-3 \mathrm{p}=0.000^{*} * *$ \\
\hline & Football $^{3}$ & 127 & 228.15 & & & & $2-4 \mathrm{p}=0,013^{*}$ \\
\hline & Individual $^{4}$ & 77 & 167.56 & & & & $3-4 \mathrm{p}=0.000^{* * * *}$ \\
\hline
\end{tabular}

When Table 3 is analysed, it is determined that there is a statistically significant difference between the fair play behaviours of the participants according to their branches in school sports, $\mathrm{X} 2(\mathrm{sd}=3, \mathrm{n}=397)=8.24$, $\mathrm{p} \leq 0.001$. When it is analysed in which groups this significant difference arises, it is determined in favour of those in the "Football" branch among those who compete in the "Football and Volleyball ( $\mathrm{U}=5824.50, \mathrm{p} \leq 0.05)$ " and "Football and Individual $(\mathrm{U}=2381.00, \mathrm{p} \leq 0.01)$ " branches. In addition to this, it is in favour of those in the "Basketball" branch among "Basketball and Individual (U=3256.50, $\mathrm{p} \leq 0.001)$ " branches.

When the fair play behaviours during-match are examined according to the branches, a statistically significant difference emerges, $\mathrm{X}^{2}(\mathrm{sd}=3, \mathrm{n}=397)=29.77, \mathrm{p} \leq 0.001$, and a result is found against the "Individual" branches among the "Individual and Volleyball (U=3385.50, $\mathrm{p} \leq 0.01)$ ", "Individual and Basketball $(\mathrm{U}=1378.50, \mathrm{p} \leq 0.001)$ " and "Individual and Football $(\mathrm{U}=1543.00, \mathrm{p} \leq 0.001)$ " branches. In addition, there is a significant statistical difference against those who are in the "Volleyball" branch between the "Volleyball and Basketball (U=2679.50, $\mathrm{p} \leq 0.001)$ " and "Volleyball and Football (U=2999.00, $\mathrm{p} \leq 0.001)$ " branches.

In addition to the statistical difference in comparing the general fair play behaviour according to the branches, $\mathrm{X}^{2}(\mathrm{sd}=3, \mathrm{n}=397)=14.81, \mathrm{p} \leq 0.001$, there is a statistically significant difference against those who compete in the "Individual" branches between those who compete in the branches of "Individual and Basketball (U=2424.50, $\mathrm{p} \leq 0.05) "$ and "Individual and Football $(\mathrm{U}=3398.50, \mathrm{p} \leq 0.001)$ ". In addition, there is a significant difference against those who compete in the "Volleyball" branch between the participants in the "Volleyball and Basketball $(\mathrm{U}=3729.50, \mathrm{p} \leq 0.05) "$ and "Volleyball and Football $(\mathrm{U}=5190.50, \mathrm{p} \leq 0.001)$ " branches.

It is a remarkable finding that the mean rank of the participants who compete in "Individual" branches in all subscales with statistically significant difference has the lowest score compared to other groups.

No statistical difference is found in the post-match fair play behaviours according to the branches, $\mathrm{X}^{2}(\mathrm{sd}=3$, $\mathrm{n}=397)=8.75, \mathrm{p} \geq 0.05$.

\section{Discussion}

As a result of the analysis, when the fair play behaviours of the participants competing in school sports are analysed according to their categories, a statistically significant difference has been found in the subscale of prematch fair play. When the average ranks of the groups are analysed, it is seen that the students participating in school sports in the "Junior B" category have the highest average rank. As the category rises, the usual behaviours can be shown as the reason for the increase in pre-match fair play behaviours. The habit of wishing success to the opposing team and the referee is a form of behaviour gained in the process. Yıldirım (2017) concluded that more than half of the participants had remarkable fair play behaviours in the pre-match fair play subscale. On the other hand, in Bozdemir (2017) study, the pre-match fair play behaviours of students in different educational levels who played basketball did not reach a significant difference compared to the grade they continued. These findings in the literature support our research.

When during-match fair play behaviours are analysed, it is revealed that the lowest mean rank is in the "Minors" category and the highest mean rank is in the "Juniors A" category. According to the results of the research, as the category rises in school sports, there is a significant difference in fair play behaviours. This may be because of the fact that the behaviours of the students who stay in the sports environment for a long time strengthen and that they mature as they grow. In Bozdemir (2017) study, it was concluded that the students studying in secondary school had higher levels of fair-play behaviour than the students studying in high school. Similarly, in the study of Efe (2006) it was discovered that the students in the lower class were at a higher level compared to the students in the upper class according to the frequency of primary school students' displaying of fair play behaviours. From here, it can be stated that as the grade level increases, the level of students displaying their fair play behaviour decreases. These results are not in line with our study.

When the post-match fair play behaviours by categories are analysed, it is understood that the highest mean rank is in the participants who compete in the "Stars" category and the lowest score is in the "Juniors A" category. 
It is revealed that post-match fair play behaviours decrease as the age and grade level increased. It has been revealed that post-match fair play behaviours decrease as the age and grade level increased. In the study conducted by Yldiran and Sezen (2006) with the participation of senior students studying in the Physical Education and Sports Teaching Programs of universities, it was revealed that a significant part of physical education teacher candidates do not find the behaviours, suitable for Fair Play, (such as "helping the referee make the right decision even if it is contrary to their own benefit and judgment", "striving for an unfair situation that opposing team is subjected to" and "not attempting to take advantage of the opponent's unfair disadvantages") "professional"; they find the behaviours that are not in conformity with Fair Play (such as "providing an unfair disadvantage by misleading the referee" and "taking away the opponent's right to play with misleading strategies") "tactically smart". As a result, it can be said that the Fair Play conception of physical education teacher candidates lags behind the 'success at all costs'. It can be said that this situation may pose a serious threat to school sports. According to Cruz et al. (2018) sports activity is thought to have an impact not only on the physical development of the person but also on moral development both positively and negatively. This can also be associated with the developing brains of young adolescents. Information processing capacity and working memory may lead to take risks or behave unethically by being corrupted by an increased reward and control system (Steinberg, 2007). In addition, it was stated by Balçıkanlı, Gülşen, and Yıldıran (2017) that sportsmanship orientation was mostly within the framework of the rule-based formal fair play approach; on the other hand, it is stated that the behaviours can change in the cases of overcome and defeat in line with the referee ruling. In the light of the information in the literature, the rise of the class level in this research can be determined as the reason for the decrease in the postmatch fair play behaviours.

When the general fair play behaviours are examined, a difference has been found in favour of those in the Stars category in the comparison between the Minors and the Stars and in favour of the Juniors A category in the comparison between the Minors and Juniors A and Juniors B and the Juniors A. As the category grows, there is a statistically difference in general fair play behaviours. It can be said that students' perception of fair play improves as they stay in the sports environment. In the study of Yildırım. (2017) it was determined that the athletes who played in school and club teams performed pre- match, during match and after-match fair-play behaviours and general fair-play behaviours in a match. It was observed that in some cases, they did not comply with fair-play due to internal or external factors. Kaya (2011) study on the concept of fair-play in school sports programs in which athletes act primarily to win and they think about violence against competitors, which is not appropriate for fairplay, is similar to its results. The research of fair-play concept in secondary school students made by Gümüs, Saraçl, Omür, Doğanay, and Kurtipek (2016) also coincides with the results.

A significant difference in the fair play behaviours of the participants according to the sports age appears only in the during-match subscale. During the match, a significant difference was observed in fair play behaviours as the age of sports grew. This result is consistent with the findings of the previous variables. In his study conducted in 2006, Efe found that the frequency of displaying the pre-match fair play behaviours of male students than female students, of 2 nd grade students than 1st grade students, and of the ones whose branch is football than those whose branch is volleyball was higher. In the study conducted by Bronikowska et al. (2019) fair play behaviours of amateur and professional athletes were measured as pre-tests and it was revealed that professional athletes had higher fair play levels. In the light of this data, considering the relationship between sports age and professionalism and experience, it is expected that fair age behaviour will increase with rising sports age. It can be said that the findings of this research overlap with the emerging results indirectly.

In the analysis of fair play behaviours according to the branch, a significant statistical difference was found between the groups in pre-match, during-match and general fair play behaviours. In all subscales with significant differences, it is seen that the highest scores according to the mean rank is in the football branch and those in basketball, volleyball respectively, and the lowest scores those who compete in the individual branches. In his study, Efe (2006) examined the frequency of displaying fair-play behaviours of elementary school students participating in inter-school competitions and stated that those whose branch is football were more likely to display fair-play behaviours than those in volleyball branch. In addition, the lack of similar findings in the literature suggests that there may be different parameters affecting fair play behaviours. In the study conducted by Mary, Alexandra, and Kimon (2007) it was stated that verbal attack behaviours of physical education teachers were negative predictors of students' fair play behaviours. Likewise, performance and outcome goals and the social support perceived from the families, teachers and friends can be seen as the other factors that affect moral and therefore fair play behaviours of the athletes (Aksoy, Ozcan, \& Coknaz, 2018; Vansteenkiste, Mauratidis, \& Lens, $2010)$.

\section{Conclusion and Suggestions}

The information revealed by this study can be shown as a rich source of information for researchers trying to explain the relationship between school sports and fair play, which are extremely important in terms of education. Some suggestions can be made as a result of this study, where fair play behaviours of students participating in school sports varies according to categories, sports age and branch. Further development of the curriculum in fair play education in schools can increase the frequency of fair play behaviour. With in-service trainings to be given to physical education teachers and coaches, fair play behaviours can be extended. For fair play behaviours that vary according to branch, sports age and categories, fair play education can be adapted according to their development periods. Thus, fair play behaviours that will be put into practice with school sports, which is one of the most important factors of education, can be made widely observable in the society after education.

\section{References}

Adilogullari, G. E., Hakkı, U., Enes, B., \& Ihsan, K. (2017). Relationship between violence tendency levels of $11-19$ aged children who attend to summer school and their behaviours towards fair play in sports. European Journal of Physical Education and Sport Science, 12(3), 78.

Aksoy, E., Ozcan, G., \& Coknaz, H. (2018). Perceived social support levels of students participating in school sports in secondary education institutions. International Journal of Social Research, 11(60), 693-698. 
Balçıkanlı, G. S., Gülşen, K., \& Yıldıran, I. (2017). Sportsmanship orientation in women footballers. Gazi Journal of Physical Education and Sports Sciences, 22(1-2-3-4), 1-9.

Bozdemir, O. (2017). The relationship between empathy skills and fair play behaviours of students in different educational levels playing basketball. Gazi University Institute of Educational Sciences. Master Thesis.

Bronikowska, M., Korcz, A., Pluta, B., Krzysztoszek, J., Ludwiczak, M., Łopatka, M., Bronikowski, M. (2019). Fair play in physical education and beyond. Sustainability, 11(24), 1-18.

Cruz, J., Ponseti, F. X., Sampaio, M., Gamito, J. M., Marques, A., Viñas, J., García-Mas, A. (2018). Effects of a psychology-based training programme on football grassroots coaches upon young player's sportspersonship and disposition to cheat. Sport Psychol, $27,23-27$.

Efe, Z. B. (2006). Frequency of 1 st and 2nd grade primary school students participating in inter-school competitions to exhibit their fair play behaviours. Gazi University Institute of Educational Sciences. Master Thesis.

Ford, D., Jubenville, C., \& Phillips, M. (2012). The effect of the star sports-manshipeducation module on parents' self-perceived sportsmanship behaviors in youth sport. Journal of Sport Administration and Supervision, 4(1), 1-4.

Gülfem, S. (2014). Fair play in professional sports: Sportspersonship Orientations of Futsal Players. Magazine of Philosophy, Ethics and Sports Law, 2(1), 33-49.

Gümüs, H., Saraçli, S., Omür, F., Doğanay, G., \& Kurtipek, S. (2016). Fairplay concept in secondary school students. International Journal of Science Culture and Sport, 4(2), 430-438.

Karasar, N. (2005). Scientific research method (15th ed.). Ankara: Nobel Publishing.

Kaya, S. (2011). Fair-play understanding of primary school administrators, physical education teachers and students in school sports programs: The Case of Bolu Province. Abant İzzet Baysal University, Master Thesis.

Kayışlığlu, N., Altınkök, M., Temel, C., \& Yüksel, Y. (2015). Examining the sportsmanship behaviours of secondary school students in physical education lesson: The case of Karabük province. International Journal of Social Sciences and Education Research, 1(3), 10441056.

Loland, S. (2002). Fair play in sport: A moral norm system (Vol. 14). London: Routledge.

Mary, H., Alexandra, B., \& Kimon, S. (2007). Physical education teacher's verbal aggression and student's fair play behaviors. Physical Educator, 64(2), 94-101.

Pehlivan, Z. (2004). The place and importance of school sports in developing the concept of fair play. Journal of Sportsmetre Physical Education and Sport Sciences, 2(2), 49-53.

Sezen, G., \& Yildıran, I. (2007). Investigation of physical education teachers' approaches to positive and negative behaviours related to fairplay in football. Journal of Sports Management and Information Technologies, 2(1), 1306-4371.

Steinberg, L. (2007). Risk taking in adolescence: New perspectives from brain and behavioral science. Current Directions in Psychological Science, 16(2), 55-59. Available at: https://doi.org/10.1111/j.1467-8721.2007.00475.x.

Tanriverdi, H. (2012). Sports ethics and violence. The Journal of Academic Social Science Studies, 5(8), 107 1-1093.

Vansteenkiste, M., Mauratidis, A., \& Lens, V. (2010). Detaching reasons from aims: Fair play and well-being in Soccer as a function of pursuing performance-approach goals for autonomous or controlling reasons. Journal of Sport and Exercise Psychology, 32(2), 217242. Available at: https://doi.org/10.1123/jsep.32.2.217.

Yıldıran, I. (2002). Fair-Play: its scope, appearance and development perspectives in Turkey. Gazi Journal of Physical Education and Sports Sciences, 9(4), 3-1.

Yıldıran, I., \& Sezen, G. (2006). Evaluation of physical education teacher candidates' approaches to concrete case studies that have a dilemma between sportsmanship and professionalism. Gazi Journal of Physical Education and Sports Sciences, 11(3), 3-14.

Yıldırım, M. (2017). Determining the fair-play understanding of sportsmen playing in school and club teams in universities: The case of Eskişehir Osmangazi University. İönü University, Journal of Physical Education and Sports Sciences, 4(1), 01-15. 